\title{
Edible films based on aqueous emulsions of low-methoxyl pectin with recovered and purified sunflower waxes
}

\author{
Running Tittle: Films from emulsions of low-methoxyl pectin and recovered sunflower \\ waxes \\ Mayra C. Chalapud ${ }^{1,2,3^{*}}$. Erica R. Baümler ${ }^{1,2}$. Amalia A. Carelli ${ }^{1,2}$ \\ 1 Departamento de Ingeniería Química, Universidad Nacional del Sur, (UNS). \\ 2 Planta Piloto de Ingeniería Química - PLAPIQUI (UNS-CONICET) Bahía Blanca, Argentina. \\ 3 Present address: Instituto de Investigaciones en Ciencia y Tecnología de Materiales - \\ INTEMA (UNMdP-CONICET) Mar del Plata, Argentina.
}

* Correspondence to: PLAPIQUI (UNS-CONICET), Camino La Carrindanga km. 7, CC 717, 8000 Bahía Blanca. Argentina. Phone: (54-291) 4861700. Fax: (54-291) 4861600. E-mail: mchalapud@plapiqui.edu.ar

\begin{abstract}
BACKGROUND: Edible films were obtained from aqueous emulsions prepared with low-methoxyl pectin at different concentrations $\left(10,20\right.$ and $\left.30 \mathrm{~g} \mathrm{~kg}^{-1}\right)$ and two sunflower wax samples recovered from two waste samples of filter cakes produced in the winterization process of sunflower oil. The two sunflower waxes samples recovered (from the normal hybrid, NSFW and from the high-oleic hybrid, HOSFW) were added in three proportions $(0.1,0.2$ and $0.3 \mathrm{~g} / \mathrm{g}$ pectin). Films were evaluated according to their structure, water resistance, water vapor permeability, mechanical properties and thermal behavior.

RESULTS: In general, good dispersion of the lipid material was observed in the cross sections of the film. Increase in the water resistance (lower swelling index and water adsorption) was associated with a greater pectin content crosslinked with $\mathrm{Ca}^{+2}$ and the hydrophobic nature of waxes. The reduction in water vapor transfer rates was

This article has been accepted for publication and undergone full peer review but has not been through the copyediting, typesetting, pagination and proofreading process which may lead to differences between this version and the Version of Record. Please cite this article as doi: $10.1002 /$ jsfa.10298
\end{abstract}


influenced by the effect of the wax addition, their fatty acid composition and their good distribution on the film. More resistant, rigid and less flexible films were obtained with lower pectin content, finding an inverse relationship between tensile strength and elongation percentage values.

CONCLUSION: These results evidence a promising alternative in the development of innovative strategies to valorize sunflower waxes derived from waste material.

Keywords: edible films; recovered sunflower waxes; low-methoxyl pectin; normal sunflower wax, high-oleic sunflower wax. 


\section{INTRODUCTION}

At present, food packaging uses conventional materials, which have high availability, relatively low cost, good mechanical behavior and barrier properties. ${ }^{1}$ However, these materials not are fully recyclable or biodegradable and have adverse effects on the environment that imply human health and ecological risks. $^{2}$ This situation has encouraged research into alternative or complementary uses of biodegradable and edible materials derived from renewable sources, byproducts or waste from the food industry. ${ }^{3}$ In this field, innovative studies have been developed about edible films and coatings, which emerge as new applications or reinforcements to existing technologies. ${ }^{4-7}$ Edible films primarily protect food against chemical and physical deterioration such as oxidation, microbial growth, dehydration, and changes and/or loss of aroma and flavor, which are promoted by migration of water vapor, oxygen, ethylene, etc. ${ }^{8}$

The functional properties of edible films depend on the nature of the material, which can be based on polysaccharides, proteins, lipids and resins, ${ }^{9}$ and also include solvents such as water or ethanol and food grade additives such as plasticizers or surfactants to maintain edibility and food safety. ${ }^{7,8}$ Pectin, like all polysaccharides, due to its hydrophilic nature, exhibits a small surface activity at the water-oil interface, which is why it is generally not considered as an emulsifying agent itself. ${ }^{10}$ However, its ability to stabilize oil-in-water $(\mathrm{O} / \mathrm{W})$ emulsions has been studied, ${ }^{11,12}$ demonstrating that it is a component capable of reducing the interfacial tension between the phase lipid and the aqueous phase, being able to be efficient in the preparation of emulsions. ${ }^{13}$ For this feature and other important characteristics, for example biodegradability, biocompatibility, edibility, gelation, and selective gas permeability, among others, ${ }^{14,15}$ pectin have been used extensively in edible film formulations.

Lipids are considered barriers that limit water vapor migration between food and the environment since they provide hydrophobicity to the films. Several studies have researched the incorporation of lipid materials such as waxes (candelilla and carnauba 
waxes, beeswax and paraffin wax) in edible film formulations for fruits and vegetables, observing some advantages, for example dehydration control, microbial stability, decrease in surface abrasion during handling, and improved appearance (brightness). ${ }^{16-18}$ Chalapud et al., ${ }^{19}$ recovered and characterized sunflower waxes from filter cakes obtained by a sunflower oil winterization process, which allowed to determine their composition for potential uses in different technologies such as edible coatings and films. Lipids are included in edible film formulation together with proteins and polysaccharides (hydrophilic materials) because they do not form a strong and self-supporting matrix by themselves. ${ }^{16,17}$ Barrier properties such as water vapor permeation depend on the relationship between the hydrophilic and hydrophobic material, and the migration generally occurs through the hydrophilic or polar portion of the film. ${ }^{20}$

In order to achieve lipid dispersion in the protein or polysaccharide matrix, the films can be formed from stable emulsions. ${ }^{21}$ This film-forming technique requires a single drying step, compared to the two drying steps or more involved in process of forming bilayer films. ${ }^{16,22}$ Particularly in the casting method, the emulsion is distributed on a flat and non-stick surface, followed by the drying and subsequent separation of the film. ${ }^{7}$ The preparation of films from calcium pectinate and sunflower wax by casting was previously described by Baümler et al., ${ }^{23}$ and their results suggested that there is a limit to the amount of pectin and sunflower wax that can be included in the coating material to still produce a satisfactory film. Then their research was extended to sunflower waxes from different hybrids, considering the effect of the sunflower wax-to-pectin proportion on the emulsion stability. ${ }^{24}$ The aqueous emulsions prepared with three different concentrations of low-methoxyl pectin and sunflower wax from normal and high-oleic hybrids at three proportions presented good physical properties and stability for their potential use in edible film applications.

In the present study, edible films were prepared from the aqueous emulsions previously evaluated by Chalapud et al., ${ }^{24}$ using the casting method. The aim of this 
study was to evaluate the structure, water resistance, mechanical properties and thermal behavior of the edible films obtained from aqueous emulsions of low-methoxyl pectin and recovered sunflower waxes from normal and high-oleic hybrids.

\section{MATERIALS AND METHODS}

\section{Materials}

Low methoxyl citrus pectin (GENU PECTIN type LM 104 AS) was provided by CP Kelco Argentina S.A. Sunflower waxes (SFW) extracted and recovered from two waste samples of filter cakes generated in the winterization of sunflower oil were used. These waste materials, a mixture of filter aid, oil and waxes, were fractionated and characterized in a previous work. ${ }^{19}$ Briefly, the waxes recovering process from waste sample consisted on washing with $\mathrm{n}$-hexane at $50^{\circ} \mathrm{C}$ for $30 \mathrm{~min}$, filtering to remove filter aid and following by successive washings with cold $n$-hexane in order to remove the oil and obtain purified waxes. Two wax samples from the normal hybrid (NSFW) and from the high-oleic hybrid (HOSFW) were obtained from the respective wastes. Glycerol was provided by Fisher Scientific (98-99\% purity, analytical grade reagent), and it was used as a plasticizer. Calcium chloride $\left(\mathrm{CaCl}_{2}\right)$, sodium bromide $(\mathrm{NaBr})$ and potassium nitrate $\left(\mathrm{KNO}_{3}\right)$ were obtained from J.T. Backer Inc. (Phillipsburg, NJ) (98-99\% purity, analytical grade reagent) and used as a crosslinking agent $\left(\mathrm{CaCl}_{2}\right)$ and to create environments of known relative humidity $\left(\mathrm{NaBr}\right.$ and $\left.\mathrm{KNO}_{3}\right)$.

\section{Film Preparation}

Pectin film-forming solutions (PA) were prepared by hydrating the low-methoxyl pectin with distilled water at three concentrations $\left(10,20\right.$ and $\left.30 \mathrm{~g} \mathrm{~kg}^{-1}\right)$, and heating the mixture at $85^{\circ} \mathrm{C}$ (temperature above the melting point of the wax) using a water bath. Once the pectin was completely dissolved, glycerol $\left(40 \mathrm{~g} \mathrm{~kg}^{-1}\right)$ was added, being the proportion respect to the pectin content: 40,20 and $13.3 \mathrm{~g} / \mathrm{g}$ pectin for 10,20 and $30 \mathrm{~g}$ $\mathrm{kg}^{-1}$ of pectin, respectively. Then, the NSFW or HOSFW at three proportions $(0.1,0.2$ 
and $0.3 \mathrm{~g} / \mathrm{g}$ pectin) were added. All samples were homogenized for $10 \mathrm{~min}$ using a Pro 200 homogenizer (Pro Oxford Scientific Inc.) at $400 \mathrm{xg}$, maintaining the temperature at $85^{\circ} \mathrm{C}$ to avoid wax crystallization. Approximately $25 \mathrm{~g}$ of PA/SFW solution was poured into Petri dishes of $10.5 \mathrm{~cm}$ diameter and allowed to dry at $50{ }^{\circ} \mathrm{C}$ for $20 \mathrm{~h}$, obtaining a thin film. The dried films were then immersed in approximately $30 \mathrm{~g}$ of a $20 \mathrm{~g} \mathrm{~kg}^{-1} \mathrm{CaCl}_{2}$ solution and allowed to stand for $30 \mathrm{~min}$ in order to promote the reaction of the calcium with the galacturonic acid in the pectin film, forming crosslinked pectin films. The Petri dishes containing the pectin film with SFW were rinsed three times with distilled water to remove calcium residues, then the films were peeled off from the dishes and conditioned at $57 \%$ relative humidity $(\mathrm{RH})$ by placing them in a desiccator over a saturated solution of $\mathrm{NaBr}$. Control films without waxes were prepared following the same procedure described above. Three films were prepared for each condition. Pectin films with addition of NSFW and HOSFW called NF and HOF were obtained, respectively.

\section{Film Characterization}

\section{Thickness}

The thickness of the films was measured using a digital micrometer (Asimeto model) with an accuracy of $0.001 \mathrm{~mm}$. Five measurements were taken at different positions (center and perimeter) of each film sample in order to determine the mean values. Mean film thickness was used to calculate the water vapor permeability (detailed later) and to estimate the transversal area required as datum for the software of the texture analyzer used for determination of mechanical properties.

\section{Microstructural Analysis}

The microstructure of the films was analyzed with a scanning electron microscope (LEO EVO 40XVP, Cambridge, 2004). The samples were fixed to a coverslip and covered with a thin layer of gold in a cathode sputtering device (Pelco 91000). Digital 
images were obtained at $5.0 \mathrm{kV}$ using $2000 \mathrm{x}$ magnification. Microphotographs of the top surface and cross-sections of the films were taken.

\section{Swelling Index (SI)}

The swelling index of films was determined in a similar way to the procedure described by Da Silva et al., ${ }^{25}$ Films were cut in circles of $2.5 \mathrm{~cm}$ diameter, then weighed $\left(w_{i}\right)$ and immersed in $100 \mathrm{~mL}$ of stirred distilled water $\left(25^{\circ} \mathrm{C}\right)$ for $2 \mathrm{~min}$. The wet sample was wiped with filter paper to remove excess surface water and then reweighed $\left(w_{t}\right)$. The swelling index was calculated according to the following equation:

$$
S I(\%)=\frac{\left(w_{f}-W_{i}\right)}{W_{i}} \times 100
$$

For each film, three independent determinations were performed, reporting the average value with its standard deviation.

\section{Water Adsorption (WS)}

The water adsorption of the films was determined as described in a previous paper ${ }^{23}$. A specimen of film was stored at $95 \% \mathrm{RH}$ (over a saturated solution of $\mathrm{KNO}_{3}$ in distilled water, $\mathrm{a}^{\mathrm{o}} \mathrm{w}=0.95$ ) in a desiccator at $25^{\circ} \mathrm{C}$ for two weeks. The amount of adsorbed water at the end of storage time was calculated as:

$$
W S(\%)=\frac{\left(W_{f}-W_{i}\right)}{W_{f}} \times 100
$$

where $w_{i}$ is the weight of the specimen before the water absorption experiment, and $w_{f}$ is the weight after two weeks. For each film, three independent determinations were performed, reporting the average value and its standard deviation.

\section{Water Vapor Transmission Rate (WVTR) and Water Vapor Permeability (WVP)}

The water vapor transmission rate was determined gravimetrically according to the ASTM E96-00 method. ${ }^{26}$ The test films were placed on top of the permeation cells containing water $(100 \% \mathrm{RH})$, sealed with Parafilm "M" lab film (American National Can, 
Greenwich, CT) and placed in a desiccator conditioned at $12 \% \mathrm{RH}$ with silica gel (desiccant) and controlled temperature. The weight loss of the cells was recorded periodically until equilibrium was reached (15 days). The slope of the linear regression line of weight loss versus time divided by the exposed film area $\left(\mathrm{cm}^{2}\right)$ represents the WVTR $\left(\mathrm{g} \mathrm{cm}^{-2}\right.$ day $\left.^{-1}\right)$. From this result, the WVP $\left(\mathrm{g} \mathrm{mm} \mathrm{cm}^{-2}\right.$ day $\left.^{-1} \mathrm{kPa}^{-1}\right)$ was calculated as follows:

$$
W V P=\frac{(W V T R \times L)}{\Delta P}
$$

where WVTR is the water vapor transmission rate $\left(\mathrm{g} \mathrm{cm}^{-2}\right.$ day $\left.{ }^{-1}\right), L$ is the mean film thickness $(\mathrm{mm})$, and $\Delta \mathrm{P}$ is the differential partial water vapor pressure $(\mathrm{kPa})$ between both sides of the film $(\Delta \mathrm{P}=2.75 \mathrm{KPa})$. The measurements were performed in duplicate.

\section{Mechanical Properties}

The mechanical properties were measured according to the ASTM D882-91 method ${ }^{27}$ using a TA-Plus texture analyzer (Lloyds Instruments, UK). Film samples were cut into strips of $25.4 \mathrm{~mm} \times 125 \mathrm{~mm}$ and conditioned at $57 \% \mathrm{RH}(\mathrm{NaBr}$ saturated solution, $\mathrm{a}^{\mathrm{o}}{ }_{\mathrm{w}}=0.577$ ) at $25^{\circ} \mathrm{C}$ for $48 \mathrm{~h}$ prior to testing. From the mean thickness of the film was calculated its transversal area, which was incorporated as datum to the equipment software. To improve the grip of the jaws, both sides of the ends of the film samples were previously fastened on cardboard rectangles by using double adhesive tape. In all tests, the initial grip separation of the jaws and crosshead speed were $90 \mathrm{~mm}$ and 20 $\mathrm{mm} / \mathrm{min}$, respectively. Tensile strength at break (TS), elongation percentage at break (\%E) and Young's modulus (Y) were evaluated in duplicate.

\section{Thermal Behavior}

The thermal behavior of the films was examined by differential scanning calorimetry (DSC) using a Perkin Elmer Pyris 1 apparatus (USA). Samples of between 7 and 10 mg were placed on hermetically sealed aluminum DSC pans. They were equilibrated at 
$25^{\circ} \mathrm{C}$, maintaining the temperature for $2 \mathrm{~min}$, and then they were heated up to $200{ }^{\circ} \mathrm{C}$ at $10^{\circ} \mathrm{C} / \mathrm{min}$ in order to evaluate the fusion behavior. ${ }^{23}$ Two independent tests were performed on each sample.

\section{Statistical analysis}

The pectin content and wax proportion were the two factors considered to perform the statistical analysis between the film samples. Significant differences were analyzed using two-way ANOVA and Fisher's test $(\alpha=0.05)$ with the InfoStat statistical analysis software, Version $2011 .^{28}$

\section{RESULTS AND DISCUSSION}

In all the tested films, the easy of handling decreased with increasing pectin content and SFW proportion in the film forming emulsion. The films from $10 \mathrm{~g} \mathrm{~kg}^{-1}$ of pectin, with or without the addition of waxes, were peeled off from the Petri dishes with greater difficulty than the rest of the films, but in turn they had a more uniform appearance along with those prepared with $20 \mathrm{~g} \mathrm{~kg}^{-1}$ pectin. The films formed from the emulsions with the highest pectin percentage $\left(30 \mathrm{~g} \mathrm{~kg}^{-1}\right)$ were harder and more difficult to handle after storage at $57 \% \mathrm{HR}$ environment. So, films from less pectin content were less flexible as it was probed in mechanical properties section. In all the films, at first glance, it was observed that the level of opacity increased with the addition of sunflower waxes.

\section{Film Thickness}

Table 1 shows the results of the film thickness measurements. The deviations found for the thickness values are related to differences between measurements of the same film and may be due to the presence of discontinuity surfaces, especially when the wax proportion increased (this will be discussed in microstructure results). Mean values ranged between 56 and $359 \mu \mathrm{m}$ for NF and between 49 and $303 \mu \mathrm{m}$ for HOF, with 
these values being higher than those found for the control films for each pectin level (48-174 $\mu \mathrm{m})$. For NF and HOF, interaction between the factors (pectin level and wax proportion) was observed $(p<0.05)$, and therefore a partitioned analysis was performed, finding significant differences in all cases. This interaction was not observed in a previous work where the amount of waxes was evaluated instead of the wax-topectin ratio, and where the wax-to-pectin ratio decreased when the pectin content increased. ${ }^{23}$ In the present work, the increase in pectin content in the film forming emulsion resulted in higher thickness values $(p<<0.01)$ for all the films. For a fixed pectin level, the increase in wax proportion produced the same effect on film thickness as the increase in pectin level, but less pronounced. Thus, there were no significant differences between control and the 0.1 wax proportion, whereas with a 0.3 wax proportion a significant effect of the waxes on the film thickness was observed ( $p<$ 0.05). The effect of the type of wax (normal or high-oleic) on the film thickness for each wax proportion was not significant $(p>0.05)$.

\section{Microstructure}

Micrographs of the top surface of NF and HOF films are presented in Fig. 1 and 2, respectively. The images show an irregular surface, with the waxes present in the form of small spherical shapes. In the films prepared from the lowest pectin content $\left(10 \mathrm{~g} \mathrm{~kg}^{-}\right.$

$\left.{ }^{1}\right)$ (Fig. 1A, 1D, 2A and 2D), some wax-free spaces can be observed, which correspond to the support matrix or pectin. As the pectin content of the emulsion and the wax proportion increased, the formation of wax clusters without the presence of wax-free spaces was observed. From previous studies, it was stated that the coalesce process in the film forming emulsion is promoted by the increase in waxes and pectin content. ${ }^{24}$ As explained in that work, the coalescence process in emulsions is determined by the breaking of the interfacial membrane that surrounds the particles, generating the union of those particles after their collision..$^{29,30}$ Therefore, the increase in the coalescence of the emulsion and so the cluster formation in the film may be due to both that the pectin 
content was not enough to achieve the complete saturation of the surface particles and that the viscosity increase of the continuous phase -due to pectin increment- did not reduce the particle movement generated over time.

Cross section images of the films (NF and HOF) are shown in Fig. 3 and 4. In general they reveal waxes deposited towards the top surface, but as the wax proportion increased, the waxes can be observed distributed and dispersed in the middle and lower areas of the films.

These films were prepared from emulsions whose stability analysis was evaluated by Chalapud et al., ${ }^{24}$ In their analysis, creaming phenomenon or lipid migration towards the upper part was observed in all the studied emulsions due to the difference in density between the waxes and the pectin matrix. In the present work, creaming was evident in the drying stage of the films, forming a not very well defined interface layer. As the wax proportion and pectin content in the emulsion increased, waxes were distributed in the middle zone of the films, forming larger particles (Fig. 3 and 4). Despite this phenomenon, in general, for both films (NF and HOF) good dispersion of the lipid material was observed in the cross-sections of the films, especially in those form emulsion with high pectin content and wax proportion. This good dispersion would limit the water migration through the hydrophilic matrix and it would influence the barrier properties and water resistance of the films due to "apparent tortuosity". ${ }^{31}$

\section{Swelling Index and Water adsorption}

The swelling index (SI) and water adsorption (WS) of the films are shown in Table 2. The time of immersion in water $(2 \mathrm{~min})$ was sufficient to produce swelling of all films. No significant differences were found between the SI values of the control films $(10,20$ and $30 \mathrm{~g} \mathrm{~kg}^{-1}$ of pectin). These values were lower than those observed for NF with 0.1 wax proportion, and higher than those for HOF for all wax proportions. Interactions between the factors were observed ( $p<0.01$ ); therefore a partitioned analysis was performed, finding significant differences between pectin content and wax proportion of 
the film forming emulsions. The increase in pectin content resulted in lower SI values. Pectin is a hydrophilic substance, and the gel formation from low-methoxyl pectin involves electrostatic junctions with $\mathrm{Ca}^{+2}$ ions (generation of crosslinking sites), leaving some $\mathrm{OH}^{-}$free groups to form hydrogen bonds with water and produce their retention. ${ }^{23}$ According to Sriamornsak and Kennedy, ${ }^{32}$ a reduction in the crosslinking degree of gel formation leads to a lower retraction force, allowing for the absorption of more water, and as a result achieving a greater swelling of the pectin films. If the crosslinking degree increases by varying the number of pectin molecules due to the augment of the pectin concentration, then there are more sites where the formation of calcium crosslinks is possible and therefore SI values of pectin films decrease. ${ }^{33}$ In addition, for both types of films (NF and HOF) SI values had a significant decreasing tendency with increasing wax proportion (from 0.1 to 0.3 ). This behavior is explained by reduction of affinity of polysaccharide matrix toward water molecules due to the hydrophobic nature of sunflower waxes, which could interact with pectin homogalacturonan sequences probably due to formation of "apolar pockets" along the pectin molecule where the wax could be entrapped, resulting in an interaction limited between carboxyl groups of pectin and water molecules, ${ }^{34-36}$ a decrease in film volume, and therefore in a lower SI. Water adsorption values were in the $17.77-35.27 \%$ range for NF, $13.22-27.66 \%$ for HOF, and $19.81-29.93 \%$ for control films. As the statistical analysis revealed an interaction between the factors $(p<0.01)$, the analysis was partitioned, observing in all films significant differences between the pectin content and wax proportion used in the film forming emulsion. In general, WS values decreased as pectin level increased, with this behavior being in agreement with the SI results (Table 2). In fact, when pectin content of the emulsion increases, the cross-linking degree is higher, and water adsorption decreases. ${ }^{32}$

The effect of wax proportion on the water adsorption capacity of the films did not present a definite trend, and it was not significant on NF films from $10 \mathrm{~g} \mathrm{~kg}^{-1}$ pectin $(p<$ 0.05). NF from 20 and $30 \mathrm{~g} \mathrm{~kg}^{-1}$ pectin presented significantly different and higher 
values than those observed for control films with 0.1 and 0.2 wax proportions, respectively $(p<0.05)$. WS values of the control films were higher than those found for HOF from with 10 and $20 \mathrm{~g} \mathrm{~kg}^{-1}$ pectin. However, HOF from $30 \mathrm{~g} \mathrm{~kg}^{-1}$ pectin showed a different behavior: the addition of waxes at 0.1 proportion produced a reduction in WS, and when that proportion was increased to 0.2 and 0.3 , the WS values were similar to those of the control sample. The SI and WS values were higher than those reported in a previous work, ${ }^{23}$ even though the incorporated wax-to-pectin ratio was higher. This difference can be attributed to the use of a higher concentration of glycerol in the present work. Glycerol has a hydrophilic nature; it retains and adsorbs water in the film matrix mainly due to the ability of plasticizers to form hydrogen bonds $(\mathrm{O}-\mathrm{H}) .^{37}$

\section{Water Vapor Transmission Rate (WVTR) and Water Vapor Permeability (WVP)}

WVTR and WVP values are presented in Fig. 5 and 6, respectively. Statistical analysis of the WVTR data revealed significant differences between pectin content and wax proportion $(p<<0.01)$. In the control films, the increase in the amount of pectin in the film forming emulsion did not have a significant effect on WVTR $(p>0.05)$, while in NF and HOF the increase in pectin level resulted in lower WVTR values $(p<0.01)$. WVTR decreased with increasing wax proportion, with the effect being significant for both films from $20 \mathrm{~g} \mathrm{~kg}^{-1}$ pectin and for HOF from $30 \mathrm{~g} \mathrm{~kg}^{-1}$ pectin $(\mathrm{p}<0.05)$. On the other hand, for films from $10 \mathrm{~g} \mathrm{~kg}^{-1}$ pectin, the effect of the wax addition was not significant $(p=$ 0.9356), except for NF with 0.1 wax proportion, where WVTR was higher than that obtained with 0.2 and 0.3 wax proportions. These results are related to the structure observed in the SEM images (Fig. 1A) showing wax-free spaces and small cracks that occurred around the small wax droplets, and which lead to an increase in water vapor flow through the film. In the rest of the films, the good distribution and dispersion of the lipid material observed in Fig. 3 and 4 affected the decrease in the migration rate with increasing emulsion pectin content (a stabilizer of $\mathrm{O} / \mathrm{W}$ emulsions) and wax proportion, thus confirming the "tortuosity" of the path that the water molecules must take across 
the film and that is originated by the presence of the lipid material. Studies performed by Hagenmaier and Baker ${ }^{18}$ indicated that a higher concentration of the hydrophobic component (carnauba wax) improved the barrier properties of the films. However, it is necessary that this component is distributed homogeneously in the matrix in order to reduce spaces and avoid cracks that allow for water molecule diffusion. ${ }^{23}$

The water vapor migration was also affected by the increase in plasticizer concentration, resulting in higher WVTR values for NF and HOF from $10 \mathrm{~g} \mathrm{~kg}^{-1}$ pectin and 0.2 wax proportion, compared to the value reported by Baümler et al., ${ }^{23}$ $\left(7.80 \times 10^{-2} \mathrm{mg} / \mathrm{day} \mathrm{cm}^{2}\right)$ using a smaller amount of glycerol. These results are in agreement with other works where the increase in the concentration of plasticizer increased the molecular mobility of the films and allowed for a greater diffusion of water vapor through the structure of the films. ${ }^{14,37,38}$

Significant differences were found between WVTR values for NF and HOF, especially from 20 and $30 \mathrm{~g} \mathrm{~kg}^{-1}$ pectin content $(\mathrm{p}>0.05)$. This can be attributed to the differences between the fatty acid composition of NSFW and HOSFW reported in a previous work. ${ }^{19}$ Many authors have reported that unsaturated fatty acids are less efficient in controlling water vapor migration due to their high degree of molecular mobility compared to saturated fatty acids, promoting water molecular diffusivity. ${ }^{39-41}$ According to this analysis, the WVTR values of HOF from 20 and $30 \mathrm{~g} \mathrm{~kg}^{-1}$ pectin were higher than those found for NF from the same pectin level, which can be attributed to the higher content of unsaturated fatty acids (mainly oleic acid, C18:1) and lower content of saturated fatty acids (mainly palmitic, acid C16:0) of the waxes from the high-oleic hybrid (HOSFW) compared to those from the normal hybrid (NSFW). ${ }^{19}$

The average WVP values of NF from 10 and $20 \mathrm{~g} \mathrm{~kg}^{-1}$ pectin decreased with increasing wax proportion, although this effect was statistically significant only in films from $10 \mathrm{~g} \mathrm{~kg}^{-1}$ pectin $(p<0.05)$. According to Morillon et al., ${ }^{31}$ waxes are considered the most efficient substances in water vapor permeability reduction due to their hydrophobic nature. Interaction between waxes and water molecules is very low; the 
polar structure (hydrophilic or carboxyl group, $\mathrm{COOH}$ ) of wax esters is buried inside the molecule and masked by long chains of hydrocarbons (hydrophobic nature). Thus, interactions between these molecules and water are almost negligible, and they are responsible for the esters of long-chain fatty alcohols and acids not spreading on the surface of water. ${ }^{42} \mathrm{NF}$ from $30 \mathrm{~g} \mathrm{~kg}^{-1}$ pectin and HOF from 10 and $20 \mathrm{~g} \mathrm{~kg}^{-1}$ pectin presented a statistically significant increase in WVP values with increasing wax proportion, which could be attributed to the thickness dependence of WVP (see equation 3), with these samples having a considerable increase in their thickness (Table 1) independently of the WVTR results. Similar behaviors were reported by Martin-Polo et al., ${ }^{43}$ who observed that the water vapor transfer rate of cellophane films covered with paraffin or oil decreased with thickness, while the permeability values increased. Significant differences found between WVP values for NF and HOF were derived from the same analysis performed for WVTR.

\section{Mechanical Properties}

Fig. 7,8 and 9 show the mechanical properties of the film samples. Elongation percentage values (\%E) (Fig. 7) found for control films were generally lower than those for NF and HOF for all the studied wax proportions, exhibiting a significant increase when pectin content in the film forming emulsion increased $\left(30 \mathrm{~g} \mathrm{~kg}^{-1}\right)$. Films with a 0.1 wax proportion showed a significant increase in \%E compared to the control films, indicating that the wax incorporation provides a more extensible film with less mechanical resistance (lower TS value). However, when the wax proportion was increased to 0.2 and 0.3 , no significant variation in \%E was observed with respect to the 0.1 wax proportion, that rises from the fact that the increase of wax proportion is accompanied with similar increments of Young's modulus $(\mathrm{Y})$ and tensile stress at break $(\% E=T S / Y)$. In addition, no significant effect $(p>0.05)$ of the type of wax (NSFW and HOSFW) was observed on the \%E values for NF and HOF. 
Tensile stress values (TS) (Fig. 8) for control, NF and HOF decreased significantly with pectin content from the film forming emulsion, finding higher values with $10 \mathrm{~g} \mathrm{~kg}^{-1}$ pectin content. Mechanical properties are associated with the nature and chemical structure of the materials composing the film. ${ }^{44}$ According to Kester and Fennema, ${ }^{45}$ an increase in structural cohesion results in a reduction of the flexibility of the film, and thus in the \%E value. In this sense, the molecular structure formed by electrostatic bonds with $\mathrm{Ca}^{+2}$ ions in the films from $10 \mathrm{~g} \mathrm{~kg}^{-1}$ pectin was denser and more resistant (higher TS and lower \%E) than those formulated from 20 and $30 \mathrm{~g} \mathrm{~kg}^{-1}$ pectin. In all films the incorporation of waxes (wax proportion of 0.1 ) produced a decreasing of TS values compared to control films. In HOF from 10 and $20 \mathrm{~g} \mathrm{~kg}^{-1}$ pectin, these values decreased significantly, but the effect of wax addition was not significant for NF from 10 and $30 \mathrm{~g} \mathrm{~kg}^{-1}$ pectin. This behavior can be attributed to some discontinuities in the polymeric matrix by those wax incorporation, which leads to a weak mechanical response. ${ }^{46}$ However, the TS values increased when wax proportion were 0.2 and 0.3 , being TS values similar to control at a wax proportion of 0.3 . This fact could due to that when the waxes are dispersed and are homogeneously distributed through the cross section of the film (Fig. 3 and 4), they interact strongly, acting as setting centers, reducing chain mobility and promoting improvement of tensile strength. ${ }^{35}$ This behavior also is reflected in an increase in the elastic modulus and stiffness of the film with 0.2 and 0.3 wax proportion. In contrast, no significant differences were found between both types of films prepared with $30 \mathrm{~g} \mathrm{~kg}^{-1}$. Significant differences in TS between NF and HOF were found for films from $20 \mathrm{~g} \mathrm{~kg}^{-1}$ pectin, with the values being lower for HOF. In general, NF and HOF exhibited similar behaviors, presenting an inverse relationship between TS and \%E. Films from $10 \mathrm{~g} \mathrm{~kg}^{-1}$ pectin showed a greater tensile strength or stress at break (TS) and a smaller deformation or elongation (\%E), considering them harder, stronger and more resistant. In addition, the behavior of the films from $10 \mathrm{~g} \mathrm{~kg}^{-1}$ pectin emulsion was not significantly affected by the addition of waxes. In contrast, films from 20 and $30 \mathrm{~g} \mathrm{~kg}^{-1}$ pectin had lower TS, and \%E increased with higher wax 
proportions, with the films being more flexible and less resistant. This inverse relationship between TS and \%E was reported by other authors working with biodegradable films based on pectin ${ }^{47}$ and films composed of gellan gum and gelatin. ${ }^{48}$ The elastic modulus (Y) values (Fig. 9) of control, NF and HOF films decreased with increasing pectin level $(p<<0.01)$. In general, the effect of the wax proportion on both films resulted in lower $Y$ values compared to their controls. As for the formulations with 10 and $30 \mathrm{~g} \mathrm{~kg}^{-1}$ pectin in NF and with $10 \mathrm{~g} \mathrm{~kg}^{-1}$ pectin in HOF, the values found for the maximum wax proportion (0.3) did not differ from the control, despite showing a drastic decrease in the $Y$ value at 0.1 and 0.2 wax proportions. On the other hand, in both films from $20 \mathrm{~g} \mathrm{~kg}^{-1}$ pectin and HOF from $30 \mathrm{~g} \mathrm{~kg}^{-1}$ pectin, the $Y$ values decreased drastically with wax addition. These results suggest that films from $10 \mathrm{~g} \mathrm{~kg}^{-1}$ pectin were more rigid, and that the addition of waxes at all pectin levels reduced this feature. Pectin (hydrophilic material) is sensitive to changes in ambient temperature and humidity. ${ }^{49}$

\section{Thermal Behavior}

Fig. 10 shows a calorimetric curve of the pectin and sunflower wax films. The melting peak of the waxes was observed at approximately $74.9-79.3^{\circ} \mathrm{C}$ for $\mathrm{NF}$ and at $75.3-80.3$ ${ }^{\circ} \mathrm{C}$ for HOF. The enthalpy change associated with wax fusion was between 12.334 and $56.235 \mathrm{~J} / \mathrm{g}$ for NF and between 18.871 and $45.088 \mathrm{~J} / \mathrm{g}$ for HOF. At temperatures above the melting point of waxes (NSFW: $76.7^{\circ} \mathrm{C}$; HOSFW: $80.53{ }^{\circ} \mathrm{C}$ ), ${ }^{19}$ a second endothermic peak was observed at approximately $116-119{ }^{\circ} \mathrm{C}$, probably associated with water evaporation. Similar results were reported for SFW/calcium pectinate films. ${ }^{23}$ The enthalpy of fusion values found for NF and HOF were lower than those for purified waxes (NSFW: $202.77 \mathrm{~J} / \mathrm{g}$, HOSFW: $204.35 \mathrm{~J} / \mathrm{g}$ ), ${ }^{19}$ indicating that part of the energy needed to melt the purified waxes is absorbed by other film components such as pectin and glycerol. The results did not provide information about the glass transition

temperature of pectin. Analysis performed by lijima et al., ${ }^{50}$ showed that pectin is a 
crystalline polymer, but when it is melted, it forms a stable amorphous structure that does not crystallize by slow cooling. In addition, they did not observe crystallization when they examined the possibility of inducing this characteristic by the presence of water.

\section{CONCLUSIONS}

Films based on low-methoxyl pectin and sunflower wax aqueous emulsions were prepared. Sunflower waxes were recovered and purified from two filter cake generated in sunflower oil winterization process. Cross section images of the microstructure of the films showed a good distribution and dispersion of the waxes as the wax proportion was increased. This behavior together with the fatty acid composition of the lipid material contributed to a decrease in the water transfer rate, indicating that sunflower waxes play an important role in the water vapor barrier properties of films. Pectin content in the film forming affected the water resistance and mechanical properties of the films, obtaining films with lower water adsorption capacity, more resistant, rigid and less flexible using the lower studied pectin level. The physical, chemical and functional characterization of the films revealed satisfactory properties for their use in the food industry as reinforcements to the protection provided by conventional packaging materials. These results provide valuable data for an increasingly broad research field with great practical applicability in fruits, meats and cheeses.

\section{ACKNOWLEDGEMENTS}

This work was supported by "Agencia Nacional de Promoción Científica y Tecnológica" [ANPCyT, PICT 520, 2016], “Consejo Nacional de Investigaciones Científicas y Técnicas" [CONICET, PIP 243, 2013] and "Universidad Nacional del Sur" [UNS, PGI 24M/152, 2017], Argentina.

\section{CONFLICT OF INTEREST STATEMENT}

The authors have declared no conflict of interest 


\section{REFERENCES}

1. Siracusa V, Rocculi $P$, Romani $S$ and Dalla Rosa M, Biodegradable polymers for food packaging: a review. Trends in Food Sci Tech 19:634-643 (2008).

2. Mahalik NP and Nambiar AN, Trends in food packaging and manufacturing systems and technology. Trends in Food Sci Tech 21:117-128 (2010).

3. Debeaufort F and Voilley A, Effect of surfactants and drying rate on barrier properties of emulsified edible films. Int J. Food Sci. Technol. 30:183-190 (1995).

4. Janjarasskul T and Krochta JM, Edible packaging materials. Annu Rev Food Sci T 1:415-448 (2010).

5. Hansen NM and Plackett D, Sustainable films and coatings from hemicelluloses: a review. Biomacromolecules 9:1493-1505 (2008).

6. Razavi SMA, Amini AM and Zahedi Y, Characterisation of a new biodegradable edible film based on sage seed gum: Influence of plasticiser type and concentration. Food Hydrocoll 43:290-298 (2015).

7. Mellinas C, Valdés A, Ramos M, Burgos N, Garrigós MdC and Jiménez A, Active edible films: current state and future trends. J. Appl.Polym.Sci. 133:1-15 (2016).

8. Pavlath AE and Orts W, Edible films and coatings: why, what, and how?, in Edible Films and Coatings for Food Applications, ed. by Embuscado ME and Huber KC. Springer, New York, USA, pp 1-23 (2009).

9. Pérez-Gago M and Krochta J, Lipid particle size effect on water vapor permeability and mechanical properties of whey protein/beeswax emulsion films. J Agr Food Chem 49:996-1002 (2001).

10. Akhtar M, Dickinson E, Mazoyer $\mathrm{J}$ and Langendorff $\mathrm{V}$, Emulsion stabilizing properties of depolymerized pectin. Food Hydrocoll 16:249-256 (2002).

11. Dickinson E, Hydrocolloids as emulsifiers and emulsion stabilizers. Food Hydrocoll 23:1473-1482 (2009). 
12. Drusch S, Sugar beet pectin: A novel emulsifying wall component for microencapsulation of lipophilic food ingredients by spray-drying. Food Hydrocoll 21:1223-1228 (2007).

13. Leroux J, Langendorff V, Schick G, Vaishnav V and Mazoyer J, Emulsion stabilizing properties of pectin. Food Hydrocoll 17:455-462 (2003).

14. Pérez Espitia PJ, Du W-X, Avena-Bustillos RdJ, Ferreira Soares NdF and McHugh TH, Edible films from pectin: Physical-mechanical and antimicrobial properties-A review. Food Hydrocoll 35:287-296 (2014).

15. Muñoz-Bonilla A, Echeverria C, Sonseca Á, Arrieta MP and Fernández-García M, Bio-based polymers with antimicrobial properties towards sustainable development. Materials 12:641 (2019).

16. Debeaufort F and Voilley A, Lipid-Based Edible Films and Coatings, in Edible Films and Coatings for Food Applications ed. by Embuscado ME and Huber KC. Springer, New York, USA, pp 135-168 (2009).

17. Baldwin E, Nisperos M, Hagenmaier R and Baker R, Use of lipids in coatings for food products. Food Technology 51:56-62 (1997).

18. Hagenmaier RD and Baker RA, Wax microemulsions and emulsions as citrus coatings. J Agr Food Chem 42:899-902 (1994).

19. Chalapud MC, Baümler ER and Carelli $A A$, Characterization of waxes and residual oil recovered from sunflower oil winterization waste. Eur J Lipid Sci Tech 119:1500608 (2017).

20. Hernandez E, Edible coatings from lipids and resins, in Edible Coatings and Films to Improve Food Quality, ed. by Krochta JM, Baldwin EA and NisperosCarriedo MO. Technomic Pub. Co, Lancaster, USA, pp 279-303 (1994).

21. Baümler ER, Carelli AA and Martini S, Physical properties of aqueous solutions of pectin containing sunflower wax. J Am Oil Chem Soc. 90:791-802 (2013). 
22. Quezada Gallo J-A, Debeaufort F, Callegarin F and Voilley A, Lipid hydrophobicity, physical state and distribution effects on the properties of emulsion-based edible films. J Membrane Sci. 180:37-46 (2000).

23. Baümler ER, Carelli AA and Martini S, Preparation and physical properties of calcium pectinate films modified with sunflower wax. Eur J Lipid Sci Tech 116:1534-1545 (2014).

24. Chalapud MC, Baümler ER and Carelli AA, Emulsions of sunflower wax in pectin aqueous solutions: Physical characterization and stability. Food Res Int 108:216225 (2018).

25. Da Silva MA, Krause AC and Kieckbusch TG, Alginate and pectin composite films crosslinked with $\mathrm{Ca}^{2+}$ ions: Effect of the plasticizer concentration. Carbohyd Polym 77:736-742 (2009).

26. ASTM, Standard Test Methods for Water Vapor Transmission of Materials (E-9695). Annual Book of ASTM Standards Vol 406, American Society for Testing and Materials:Philadelphia, USA (1995).

27. ASTM, Standard Test Methods for Tensile Properties of Thin Plastic Sheeting (D882-02). Annual Book of ASTM Standards, American Society for Testing and Materials:Philadelphia, USA (2010).

28. Di Rienzo J, Casanoves F, Balzarini M, Gonzalez L, Tablada M and Robledo yC, InfoStat versión 2011. Grupo InfoStat, FCA, Universidad Nacional de Córdoba, Argentina URL http://wwwinfostatcomar 8:195-199 (2011).

29. Rousseau D, Fat crystals and emulsion stability—a review. Food Res Int 33:3-14 (2000).

30. Walstra P, Dispersed Systems: Basic Considerations, in Food Chemistry, ed. by Fennema OR. Marcale Dekker, New York, USA, pp 95-156 (1996).

31. Morillon V, Debeaufort F, Blond G, Capelle M and Voilley A, Factors Affecting the Moisture Permeability of Lipid-Based Edible Films: A Review. Crit. Rev.Food Sci. Nutr. 42:67-89 (2002). 
32. Sriamornsak $P$ and Kennedy RA, Swelling and diffusion studies of calcium polysaccharide gels intended for film coating. Int.J.Pharm.358:205-213 (2008).

33. Marathe R, Development of controlled release antimicrobial films from low methoxyl pectin, Ed. Rutgers University-Graduate School-New Brunswick (2008).

34. Pau-Roblot C, Courtois B and Courtois J, Interactions between polysaccharides uronic acid sequences and lipid molecules. Comptes Rendus Chimie 13:443-448 (2010).

35. Nisar T, Wang Z-C, Yang $X$, Tian Y, lqbal M and Guo Y, Characterization of citrus pectin films integrated with clove bud essential oil: Physical, thermal, barrier, antioxidant and antibacterial properties. Int. J. Biol. Macromol.106:670680 (2018).

36. Alvarez-Pérez OB, Montañez J, Aguilar CN and Rojas R, Pectin-candelilla wax: An alternative mixture for edible films. J Microbiol Biotechnol Food Sci 5:167 (2015).

37. Cerqueira MA, Souza BW, Teixeira JA and Vicente AA, Effect of glycerol and corn oil on physicochemical properties of polysaccharide films-A comparative study. Food Hydrocoll 27:175-184 (2012).

38. Maftoonazad N, Ramaswamy HS and Marcotte M, Evaluation of factors affecting barrier, mechanical and optical properties of pectin-based films using response surface methodology. J Food Process Eng 30:539-563 (2007).

39. Kamper $\mathrm{S}$ and Fennema $\mathrm{O}$, Water vapor permeability of an edible, fatty acid, bilayer film. J Food Sci 49:1482-1485 (1984).

40. Fernández L, Díaz de Apodaca E, Cebrián M, Villarán MC and Maté Jl, Effect of the unsaturation degree and concentration of fatty acids on the properties of WPIbased edible films. Eur Food Res Technol. 224:415-420 (2007).

41. Jiménez $A$, Fabra $M J$, Talens $P$ and Chiralt $A$, Effect of re-crystallization on tensile, optical and water vapour barrier properties of corn starch films containing fatty acids. Food Hydrocoll 26:302-310 (2012). 
42. Kester $\mathrm{J}$ and Fennema $\mathrm{O}$, Resistance of lipid films to water vapor transmission. $J$ Am Oil Chem Soc 66:1139-1146 (1989).

43. Martin-Polo M, Mauguin C and Voilley A, Hydrophobic films and their efficiency against moisture transfer. 1. Influence of the film preparation technique. $J$ Agr Food Chem 40:407-412 (1992).

44. Phan The D, Debeaufort F, Voilley A and Luu D, Biopolymer interactions affect the functional properties of edible films based on agar, cassava starch and arabinoxylan blends. J Food Eng. 90:548-558 (2009).

45. Kester $\mathrm{J}$ and Fennema O, Edible films and coatings: a review. Food Technology (USA) 48, 47 (1986).

46. Sánchez-González L, Cháfer M, Chiralt A and González-Martínez C, Physical properties of edible chitosan films containing bergamot essential oil and their inhibitory action on Penicillium italicum. Carbohyd Polym 82:277-283 (2010).

47. Kang $\mathrm{HJ}$, Jo C, Lee NY, Kwon JH and Byun MW, A combination of gamma irradiation and $\mathrm{CaCl} 2$ immersion for a pectin-based biodegradable film. Carbohyd Polym 60:547-551 (2005).

48. Lee $\mathrm{KY}$, Shim $\mathrm{J}$ and Lee $\mathrm{HG}$, Mechanical properties of gellan and gelatin composite films. Carbohyd Polym 56:251-254 (2004).

49. Debeaufort F, Quezada-Gallo J-A and Voilley A, Edible films and coatings: tomorrow's packagings: a review. Crit Rev Food Sci 38:299-313 (1998).

50. lijima $M$, Nakamura $K$, Hatakeyama $T$ and Hatakeyama $H$, Phase transition of pectin with sorbed water. Carbohyd Polym 41:101-106 (2000). 
Table 1. Film thickness $(\mu \mathrm{m})$ of control films and films containing sunflower waxes from normal (NF) and high-oleic hybrids (HOF).

\begin{tabular}{|c|c|c|c|c|c|}
\hline \multirow{2}{*}{$\begin{array}{l}\text { Pectin } \\
\left(\mathrm{g} \mathrm{kg}^{-1}\right)\end{array}$} & \multicolumn{5}{|c|}{ Wax proportion (g/g pectin) } \\
\hline & Control films & & 0.1 & 0.2 & 0.3 \\
\hline 10 & $48 \pm 15^{\mathrm{a}, \mathrm{A}}$ & & ${ }^{A} 56 \pm 17^{\text {ab, A }}$ & ${ }^{A} 64 \pm 18^{\mathrm{b}, \mathrm{A}}$ & ${ }^{A} 70 \pm 21^{b, A}$ \\
\hline 20 & $101 \pm 40^{\mathrm{a}, \mathrm{B}}$ & NF & A $119 \pm 27^{a b, B}$ & ${ }^{A} 135 \pm 68^{a b, B}$ & A $159 \pm 72^{b, B}$ \\
\hline 30 & $174 \pm 46^{a, C}$ & & A $175 \pm 25^{\text {a, C }}$ & ${ }^{A} 297 \pm 84^{\mathrm{b}, \mathrm{C}}$ & ${ }^{A} 359 \pm 111^{b, C}$ \\
\hline 10 & $48 \pm 15^{\mathrm{a}, \mathrm{A}}$ & & $\mathrm{A} 49 \pm 16^{\mathrm{a}, \mathrm{A}}$ & ${ }^{A} 52 \pm 11^{\text {a, A }}$ & A $79 \pm 15^{b, A}$ \\
\hline 20 & $101 \pm 40^{\mathrm{a}, \mathrm{B}}$ & HOF & ${ }^{A} 103 \pm 19^{a, B}$ & A $133 \pm 18^{a b, B}$ & A $149 \pm 66^{\text {b, B }}$ \\
\hline 30 & $174 \pm 46^{\mathrm{a}, \mathrm{C}}$ & & ${ }^{A} 219 \pm 93^{a b, C}$ & ${ }^{A} 269 \pm 58^{\text {bc, C }}$ & ${ }^{A} 303 \pm 65^{C, C}$ \\
\hline
\end{tabular}

Mean values \pm standard deviation, $\mathrm{n}=5$. Values in the same row followed by different lowercase letters (wax proportion effect) are significantly different $(p<0.05)$ by Fisher's Test. Values in the same column (pectin concentration effect) followed by different uppercase letters are significantly different $(p<0.05)$ by Fisher's Test. Values in the same column preceded by different uppercase letters (comparison of type of film, NF or HOF, for each concentration of pectin and wax proportion) are significantly different $(p<0.05)$ by Fisher's Test. 
Table 2. Swelling index (\%) and water adsorption (\%) of control films and films containing sunflower waxes from normal (NF) and high-oleic hybrids (HOF).

\begin{tabular}{|c|c|c|c|c|c|}
\hline \multirow{2}{*}{$\begin{array}{l}\text { Pectin } \\
\left(\mathrm{g} \mathrm{kg}^{-1}\right)\end{array}$} & \multicolumn{5}{|c|}{ Wax proportion (g/g pectin) } \\
\hline & Control films & & 0.1 & 0.2 & 0.3 \\
\hline \multicolumn{6}{|c|}{ SI (\%) } \\
\hline 10 & $103.4 \pm 7.2^{\mathrm{a}, \mathrm{A}}$ & & ${ }^{B} 130.6 \pm 12.5^{b, B}$ & ${ }^{\mathrm{B}} 112.8 \pm 5.9^{\mathrm{a}, \mathrm{B}}$ & ${ }^{\mathrm{B}} 112.5 \pm 8.5^{\mathrm{a}, \mathrm{B}}$ \\
\hline 20 & $95.2 \pm 9.7^{\mathrm{a}, \mathrm{A}}$ & NF & B $115.9 \pm 10.0^{\mathrm{b}, \mathrm{B}}$ & ${ }^{B} 91.9 \pm 13.3^{a, A}$ & ${ }^{B} 81.5 \pm 2.2^{a, A}$ \\
\hline 30 & $87.8 \pm 7.2^{\mathrm{b}, \mathrm{A}}$ & & ${ }^{A} 89.8 \pm 3.3^{\text {b, A }}$ & ${ }^{B} 83.0 \pm 2.8^{a b, A}$ & ${ }^{B} 75.5 \pm 2.5^{\text {a, A }}$ \\
\hline 10 & $103.4 \pm 7.2^{\mathrm{d}, \mathrm{A}}$ & & ${ }^{\mathrm{A}} 93.6 \pm 5.0^{\mathrm{c}, \mathrm{B}}$ & ${ }^{\mathrm{A}} 82.2 \pm 1.9^{\mathrm{b}, \mathrm{B}}$ & ${ }^{A} 53.9 \pm 4.3^{a, B}$ \\
\hline 20 & $95.2 \pm 9.7^{\mathrm{c}, \mathrm{A}}$ & HOF & A $77.8 \pm 5.1^{\mathrm{b}, \mathrm{AB}}$ & ${ }^{\mathrm{A}} 54.8 \pm 3.9^{\mathrm{a}, \mathrm{A}}$ & ${ }^{\mathrm{A}} 46.1 \pm 7.0^{\mathrm{a}, \mathrm{B}}$ \\
\hline 30 & $87.8 \pm 7.2^{\mathrm{c}, \mathrm{A}}$ & & ${ }^{\mathrm{A}} 71.8 \pm 11.8^{\mathrm{b}, \mathrm{A}}$ & ${ }^{\mathrm{A}} 62.0 \pm 7.7^{\mathrm{b}, \mathrm{A}}$ & ${ }^{A} 29.4 \pm 3.6^{a, A}$ \\
\hline \multicolumn{6}{|c|}{ WS (\%) } \\
\hline 10 & $29.9 \pm 2.1^{\text {a, B }}$ & & ${ }^{B} 35.3 \pm 3.7^{a, B}$ & ${ }^{\mathrm{A}} 32.2 \pm 3.7^{\mathrm{a}, \mathrm{A}}$ & ${ }^{\mathrm{B}} 34.1 \pm 1.7^{\mathrm{a}, \mathrm{C}}$ \\
\hline 20 & $26.3 \pm 2.0^{\mathrm{a}, \mathrm{B}}$ & NF & ${ }^{B} 32.9 \pm 1.5^{b, B}$ & ${ }^{\mathrm{A}} 26.0 \pm 4.7^{\mathrm{a}, \mathrm{A}}$ & ${ }^{B} 25.4 \pm 2.0^{a, B}$ \\
\hline 30 & $19.8 \pm 3.1^{\mathrm{a}, \mathrm{A}}$ & & B $19.2 \pm 0.9^{a, A}$ & ${ }^{\mathrm{B}} 25.6 \pm 1.7^{\mathrm{b}, \mathrm{A}}$ & A $17.8 \pm 3.3^{\mathrm{a}, \mathrm{A}}$ \\
\hline 10 & $29.9 \pm 26.3^{\mathrm{b}, \mathrm{B}}$ & & ${ }^{A} 26.4 \pm 3.9^{\mathrm{b}, \mathrm{B}}$ & ${ }^{\mathrm{A}} 27.7 \pm 1.6^{\mathrm{b}, \mathrm{C}}$ & ${ }^{\mathrm{A}} 20.3 \pm 0.8^{\mathrm{a}, \mathrm{A}}$ \\
\hline 20 & $26.3 \pm 2.0^{b, B}$ & HOF & ${ }^{A} 25.6 \pm 1.8^{b, B}$ & $\mathrm{~A} 22.5 \pm 3.1^{\mathrm{ab}, \mathrm{B}}$ & ${ }^{\mathrm{A}} 20.5 \pm 1.3^{\mathrm{a}, \mathrm{A}}$ \\
\hline 30 & $19.8 \pm 3.1^{\mathrm{b}, \mathrm{A}}$ & & $\mathrm{A} 13.2 \pm 0.8^{\mathrm{a}, \mathrm{A}}$ & $\mathrm{A} 18.0 \pm 1.5^{\mathrm{b}, \mathrm{A}}$ & A $18.7 \pm 3.2^{\mathrm{b}, \mathrm{A}}$ \\
\hline
\end{tabular}

Mean values \pm standard deviation, $\mathrm{n}=3$. Values in the same row followed by different lowercase letters (wax proportion effect) are significantly different $(p<0.05)$ by Fisher's Test. Values in the same column (pectin concentration effect) followed by different uppercase letters are significantly different $(p<0.05)$ by Fisher's Test. Values in the same column preceded by different uppercase letters (comparison of type of film, NF or HOF, for each concentration of pectin and wax proportion) are significantly different $(p<0.05)$ by Fisher's Test. 


\section{Figure Legends}

Fig. 1

Scanning electron micrographs of NF (pectin films with sunflower waxes from normal hybrid). Top surface. pectin ( $\left.\mathrm{g} \mathrm{kg}^{-1}\right)$ - wax proportion: A. 1 -0.1; B. 1 - 0.2; C. 1 - 0.3; D. 2 - 0.1; E. 2 - 0,2.; F. 2 - 0.3; G. 3 - 0.1; H. 3 - 0.2; I. 3 - 0.3.
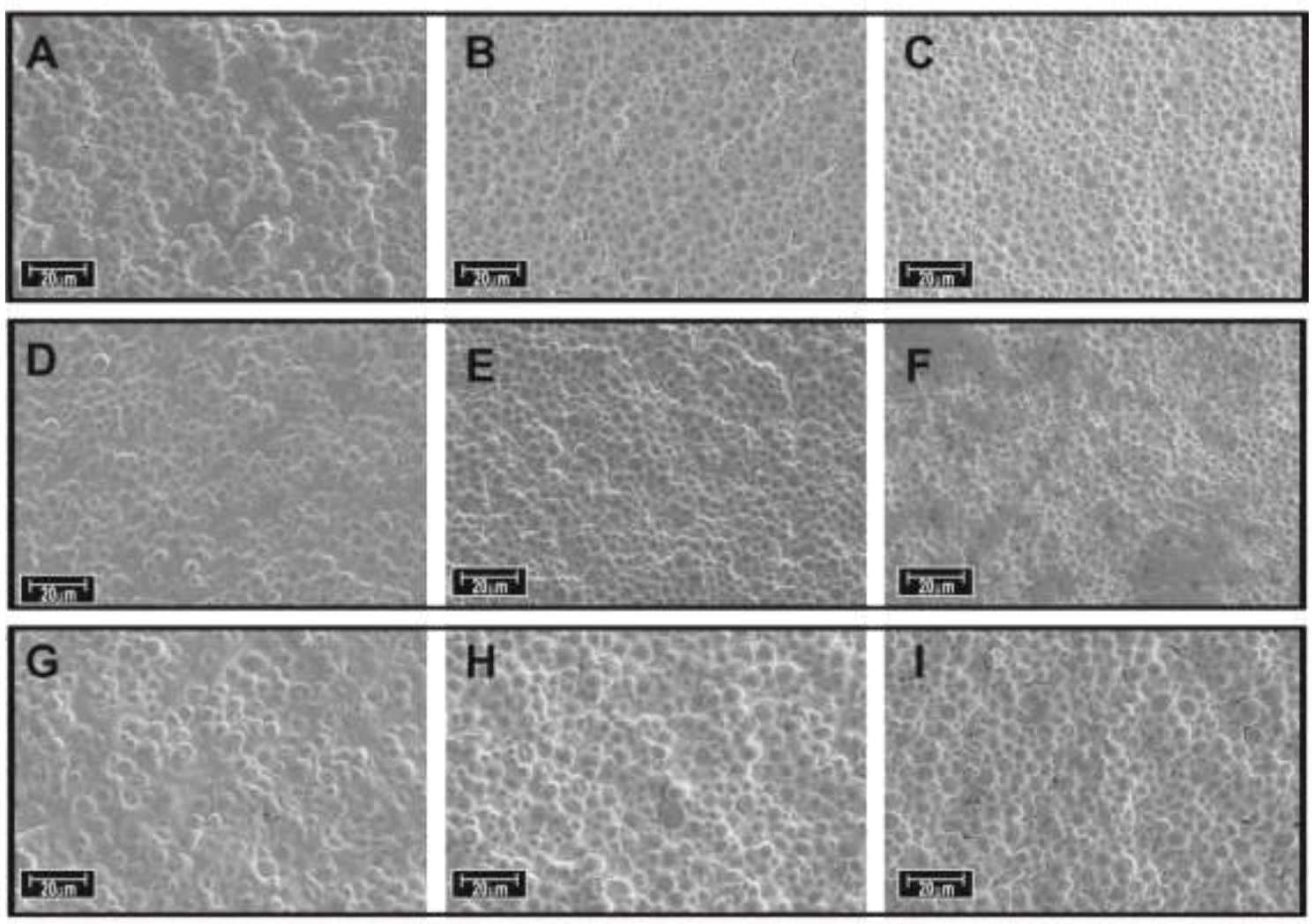

Fig. 2

Scanning electron micrographs of HOF (pectin films with sunflower waxes from higholeic hybrid). Top surface. pectin ( $\left.\mathrm{g} \mathrm{kg}^{-1}\right)$ - wax proportion: A. 1 -0.1; B. 1 - 0.2; C. 1 0.3; D. 2 - 0.1; E. 2 - 0,2.; F. 2 - 0.3; G. 3 - 0.1; H. 3 - 0.2; I. 3 - 0.3. 

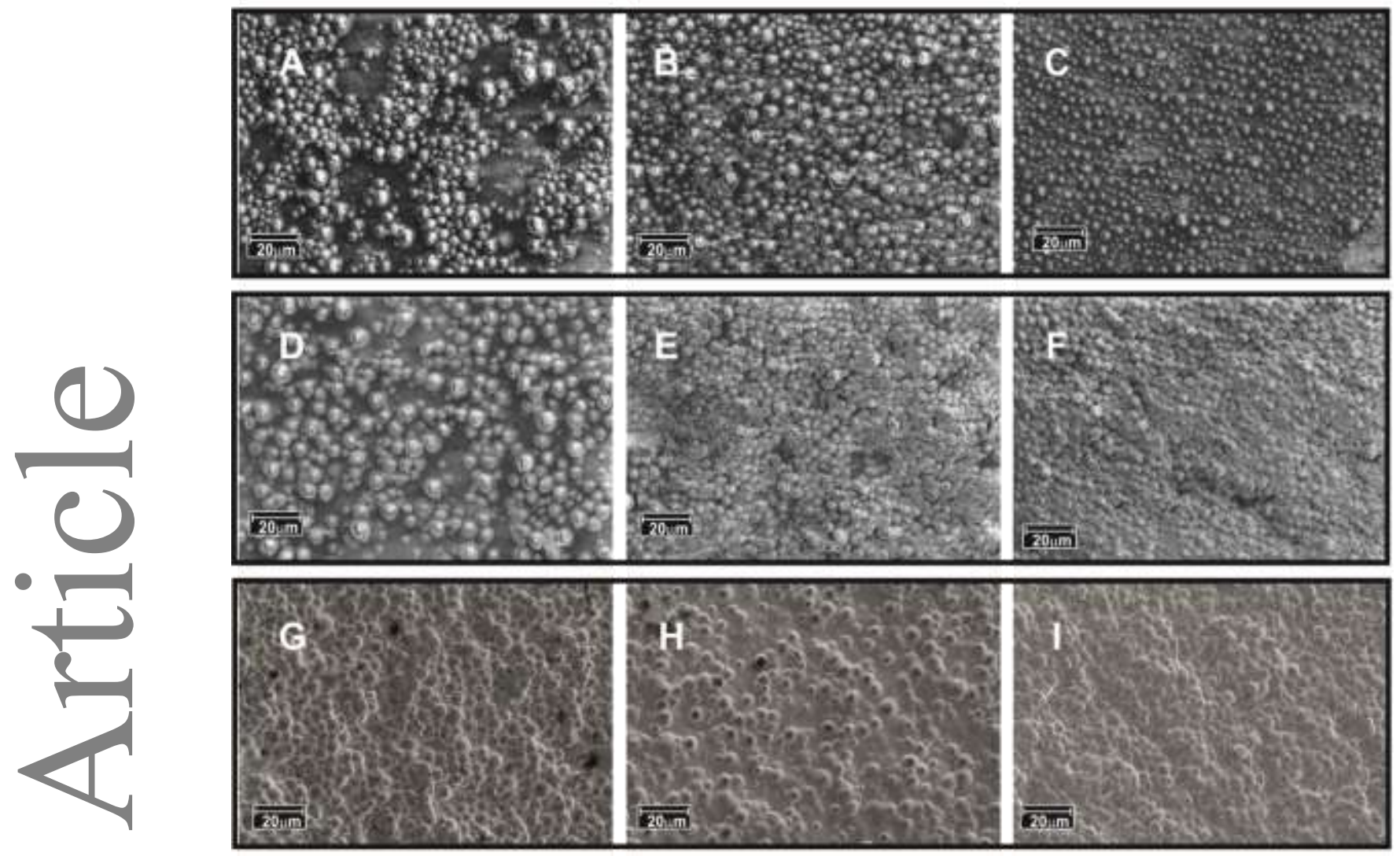

Fig. 3

Scanning electron micrographs of NF (pectin films with sunflower waxes from normal hybrid). Cross section. pectin ( $\left.\mathrm{g} \mathrm{kg}^{-1}\right)$ - wax proportion: A. 1 -0.1; B. 1 - 0.2; C. 1 - 0.3; D. 2 - 0.1 ; E. 2 - 0,2.; F. 2 - 0.3; G. 3 - 0.1; H. 3 - 0.2; I. 3 - 0.3. 

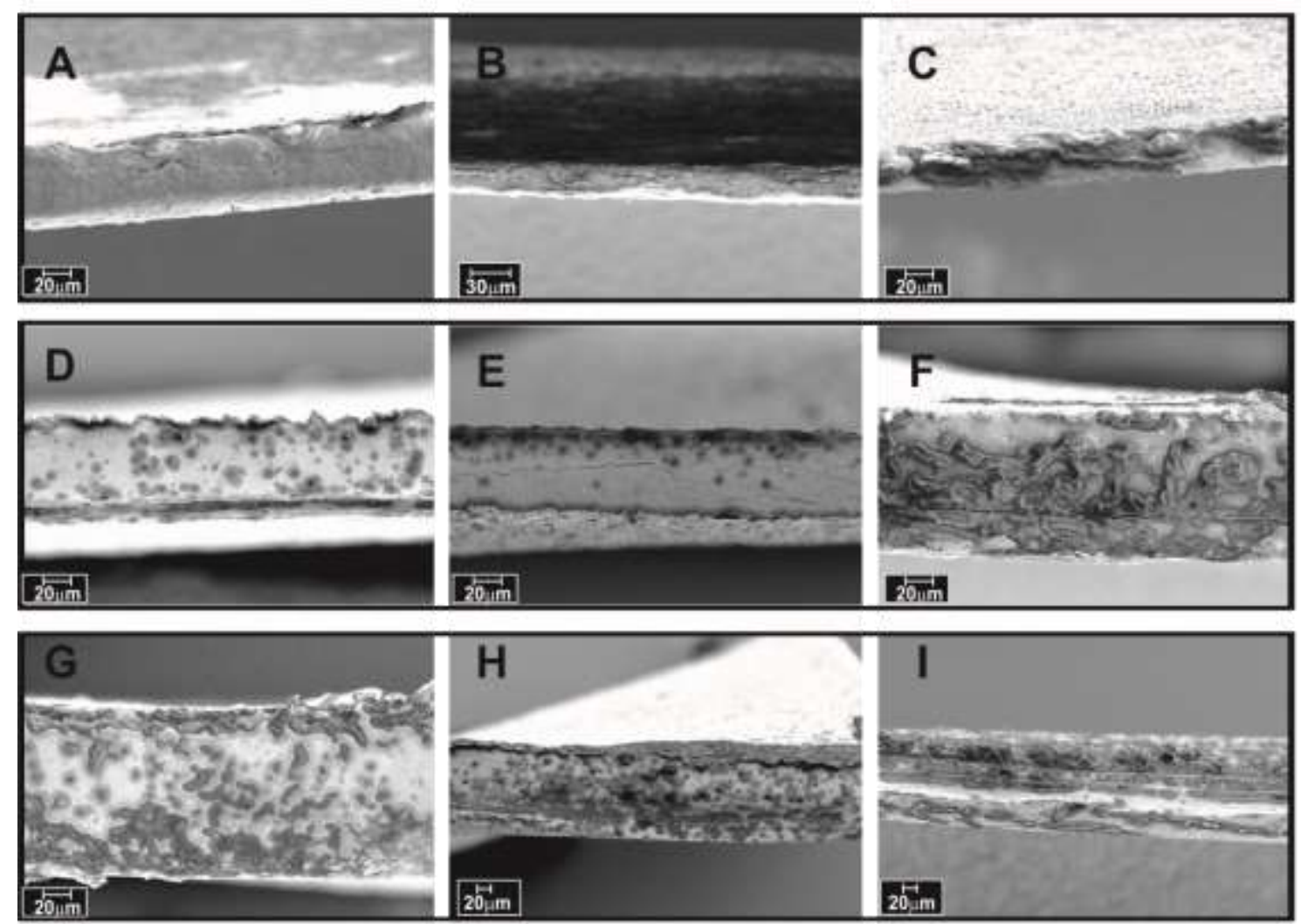

Fig. 4

Scanning electron micrographs of HOF (pectin films with sunflower waxes from higholeic hybrid). Cross section. pectin $\left(\mathrm{g} \mathrm{kg}^{-1}\right)$ - wax proportion: A. 1 -0.1; B. 1 - 0.2; C. 1 0.3; D. 2 - 0.1; E. 2 - 0,2.; F. 2 - 0.3; G. 3 - 0.1; H. 3 - 0.2; I. 3 - 0.3. 

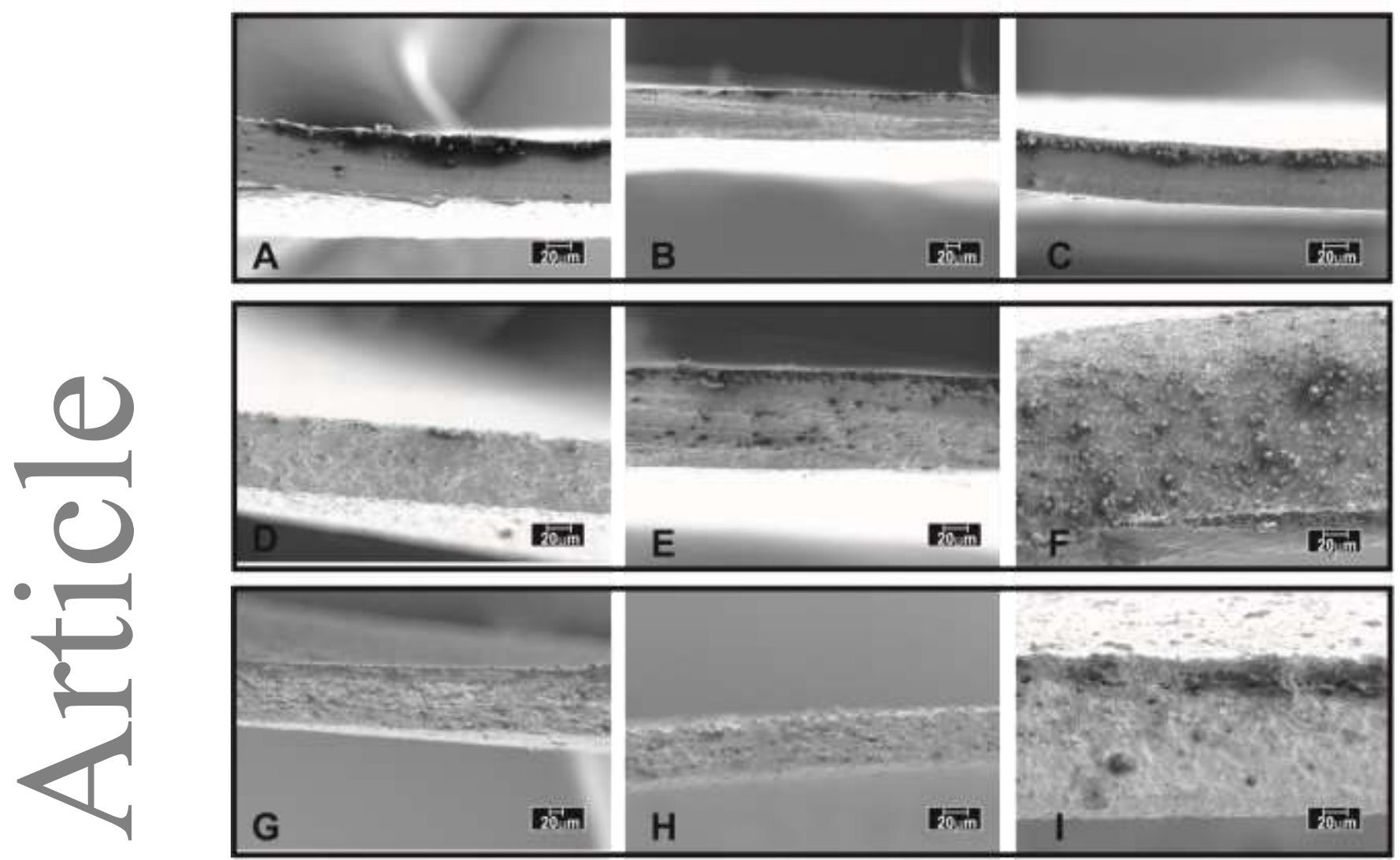

\section{Fig. 5}

Water vapor transmission rate (WVTR) of control films, A. Films containing sunflower waxes from normal (NF) and B. Films containing sunflower waxes form high-oleic hybrids (HOF). Mean values \pm standard deviation, $n=2$. Different lowercase letters (wax proportion effect), different uppercase letters (pectin concentration effect) and different bold uppercase letters (comparison of type of film, NF or HOF, in each concentration of pectin, wax proportion) are significantly different $(p<0.05)$ by the Fisher's Test.

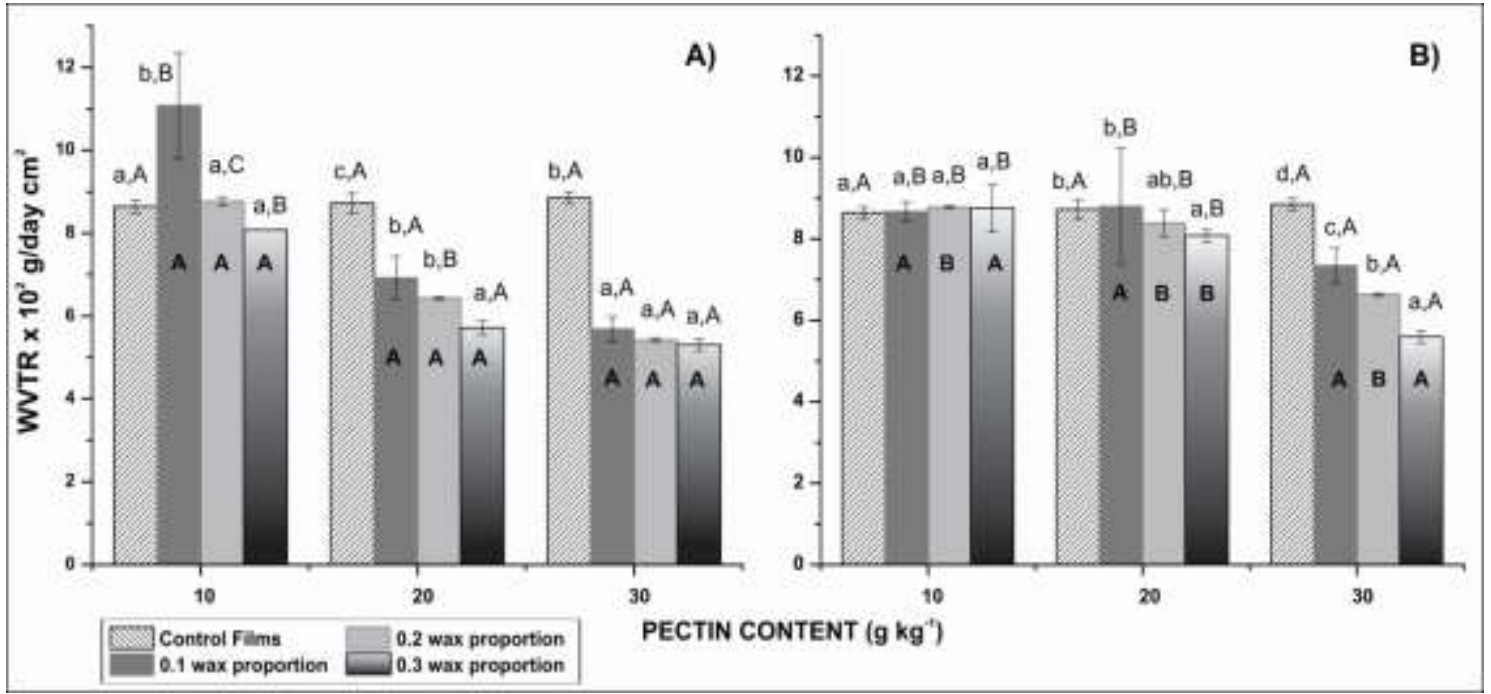


Fig. 6

Water vapor permeability (WVP) of control films, A. Films containing sunflower waxes from normal (NF) and B. Films containing sunflower waxes form high-oleic hybrids (HOF). Mean values \pm standard deviation, $n=2$. Different lowercase letters (wax proportion effect), different uppercase letters (pectin concentration effect) and different bold uppercase letters (comparison of type of film, NF or HOF, in each concentration of pectin, wax proportion) are significantly different $(p<0.05)$ by the Fisher's Test.
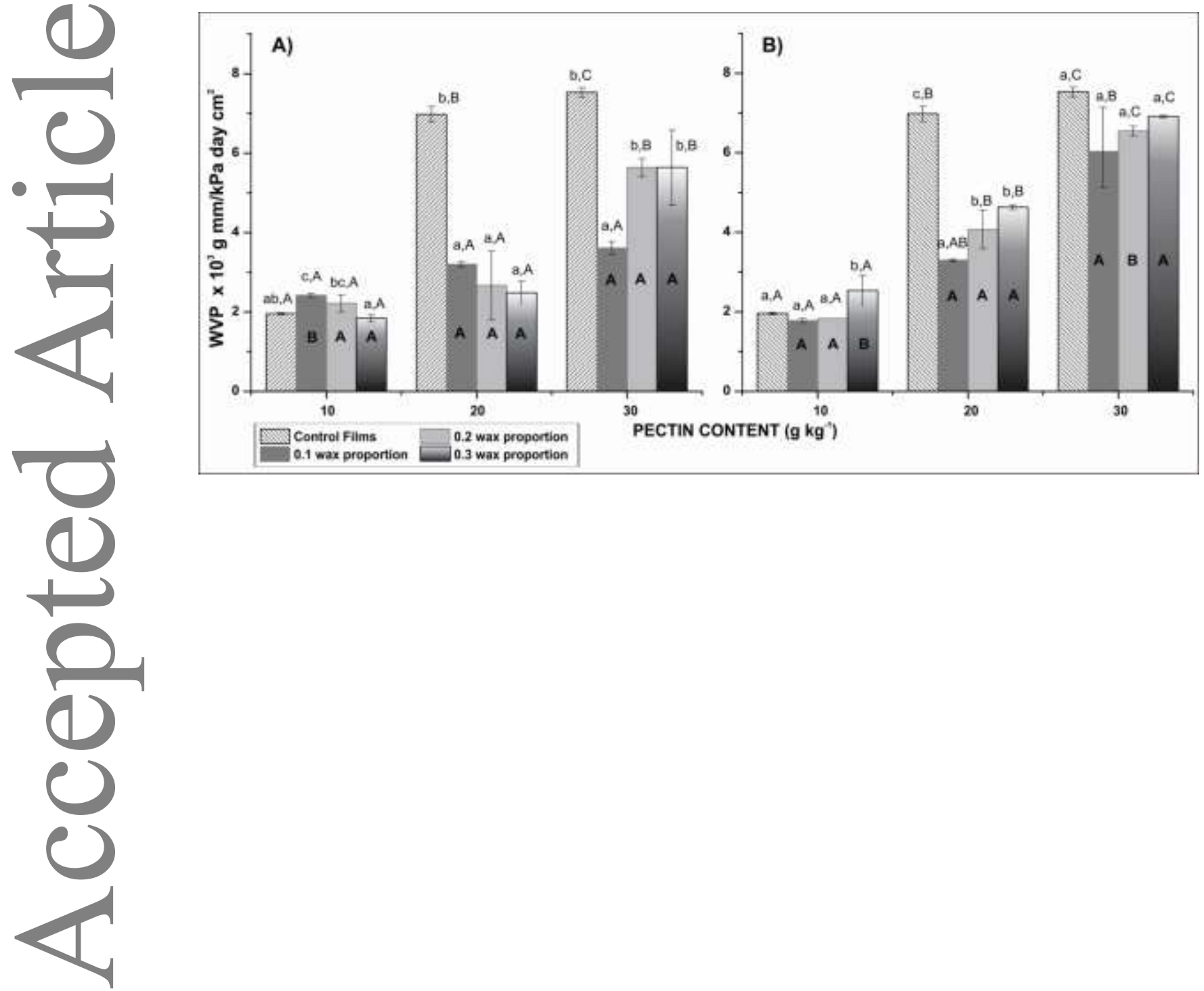
Fig. 7

Elongation percentage (\%E) of control films, A. Films containing sunflower waxes from normal (NF) and B. Films containing sunflower waxes form high-oleic hybrids (HOF). Mean values \pm standard deviation, $n=2$. Different lowercase letters (wax proportion effect), different uppercase letters (pectin concentration effect) and different bold uppercase letters (comparison of type of film, NF or HOF, in each concentration of pectin, wax proportion) are significantly different $(p<0.05)$ by the Fisher's Test.

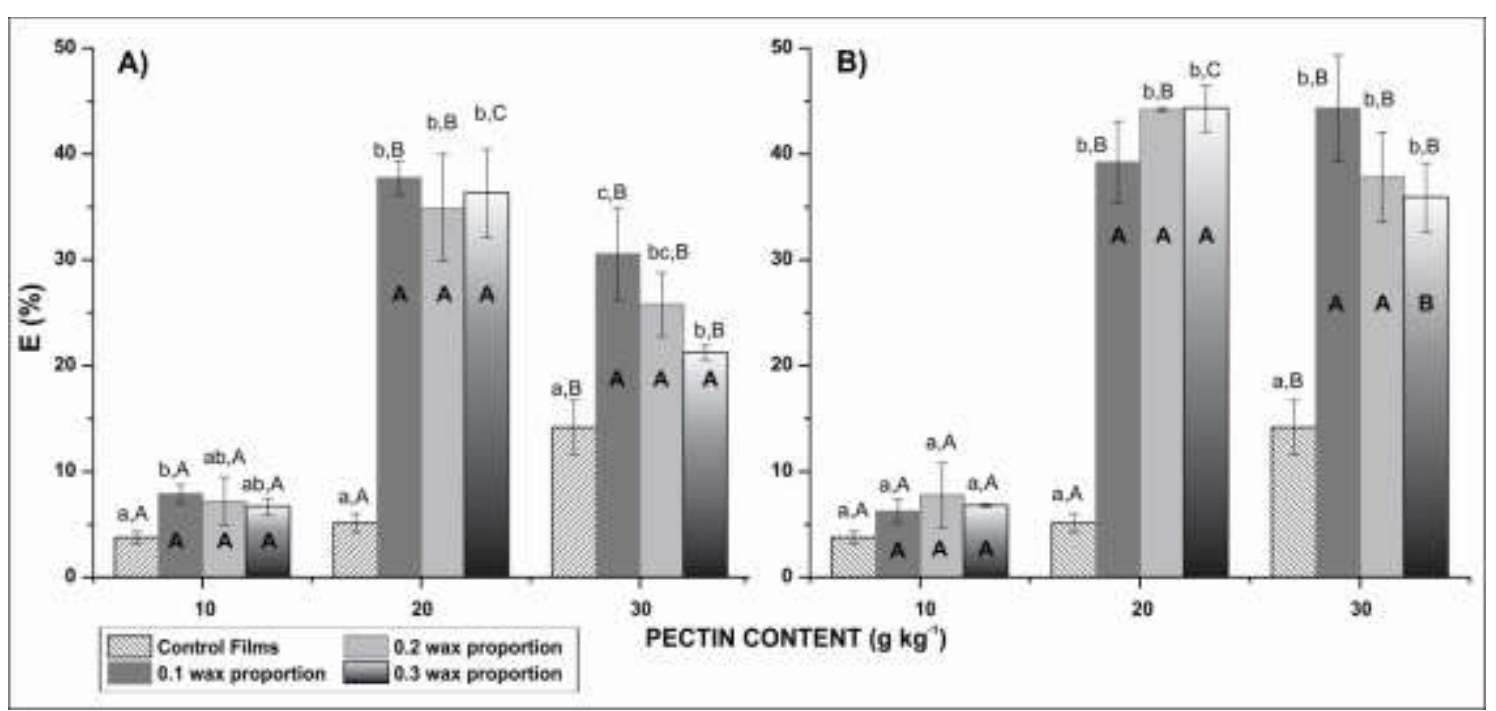


Fig. 8

Tensile stress (TS) of control films, A. Films containing sunflower waxes from normal (NF) and B. Films containing sunflower waxes form high-oleic hybrids (HOF). Mean values \pm standard deviation, $n=2$. Different lowercase letters (wax proportion effect), different uppercase letters (pectin concentration effect) and different bold uppercase letters (comparison of type of film, NF or HOF, in each concentration of pectin, wax proportion) are significantly different $(p<0.05)$ by the Fisher's Test.
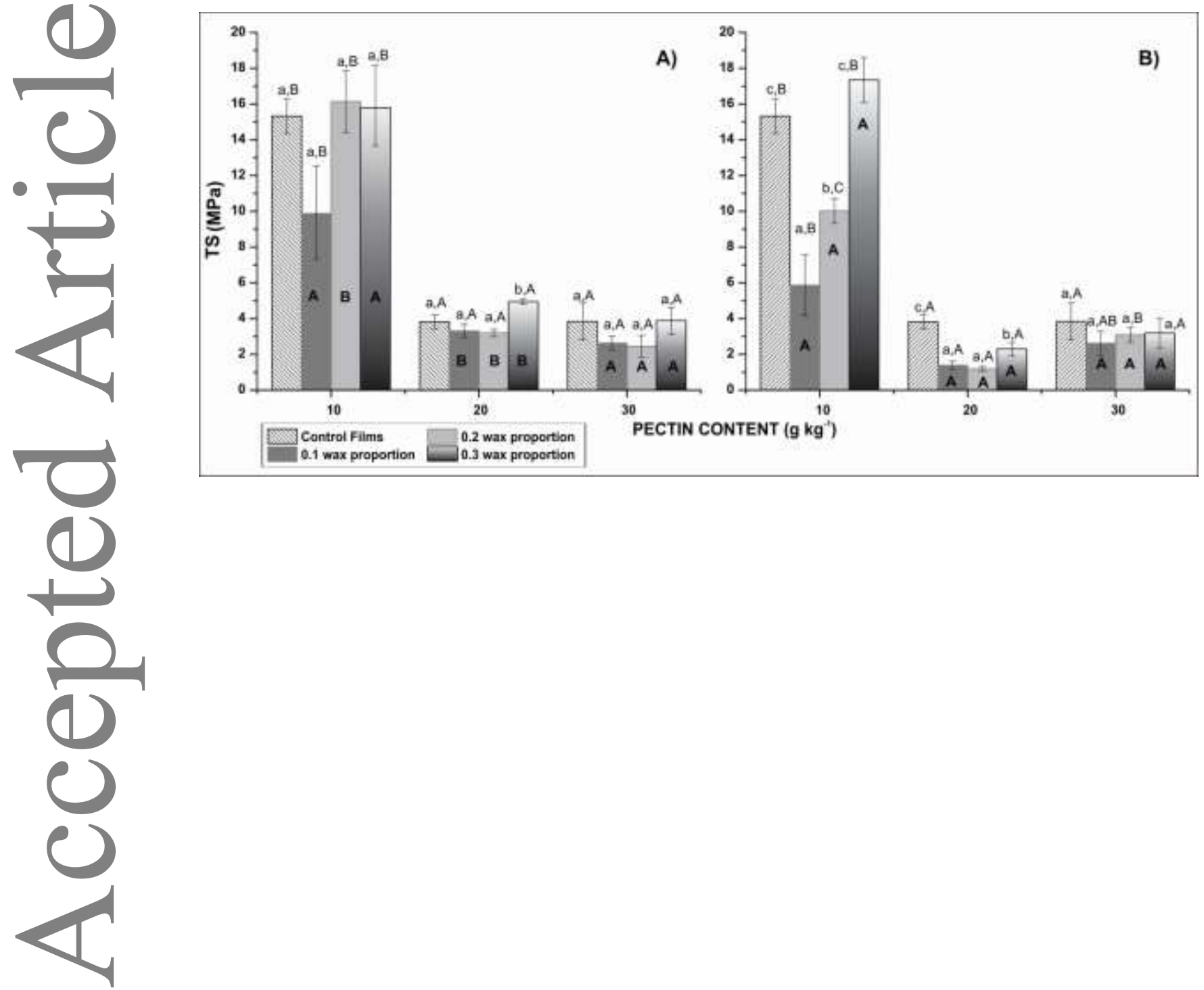
Fig. 9

Elastic modulus $(\mathrm{Y})$ of control films, A. Films containing sunflower waxes from normal (NF) and B. Films containing sunflower waxes form high-oleic hybrids (HOF). Mean values \pm standard deviation, $n=2$. Different lowercase letters (wax proportion effect), different uppercase letters (pectin concentration effect) and different bold uppercase letters (comparison of type of film, NF or HOF, in each concentration of pectin, wax proportion) are significantly different $(p<0.05)$ by the Fisher's Test.

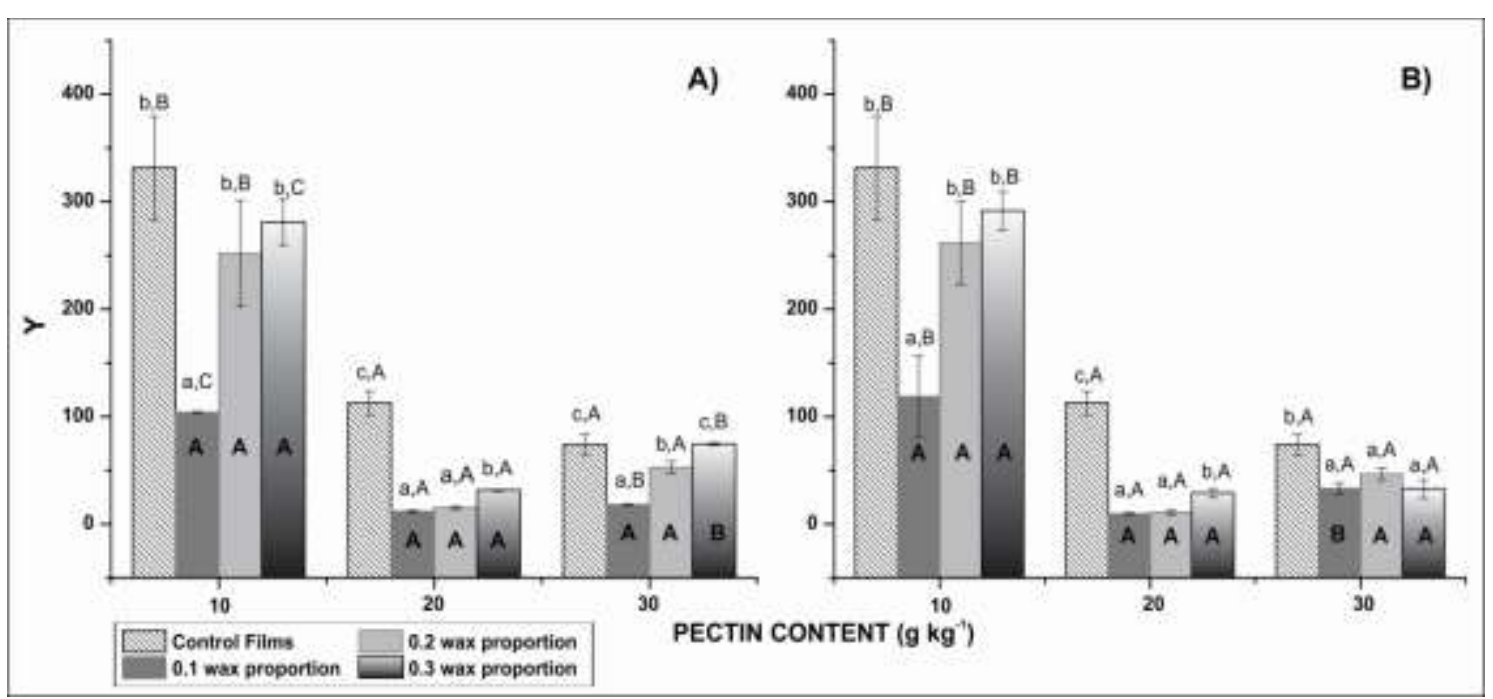


Fig. 10

Representative thermal behavior of films prepared with low-methoxyl pectin and sunflower waxes. A. NF (Pectin films with sunflower waxes from normal hybrid) B. HOF (Pectin films with sunflower waxes from high-oleic hybrid).

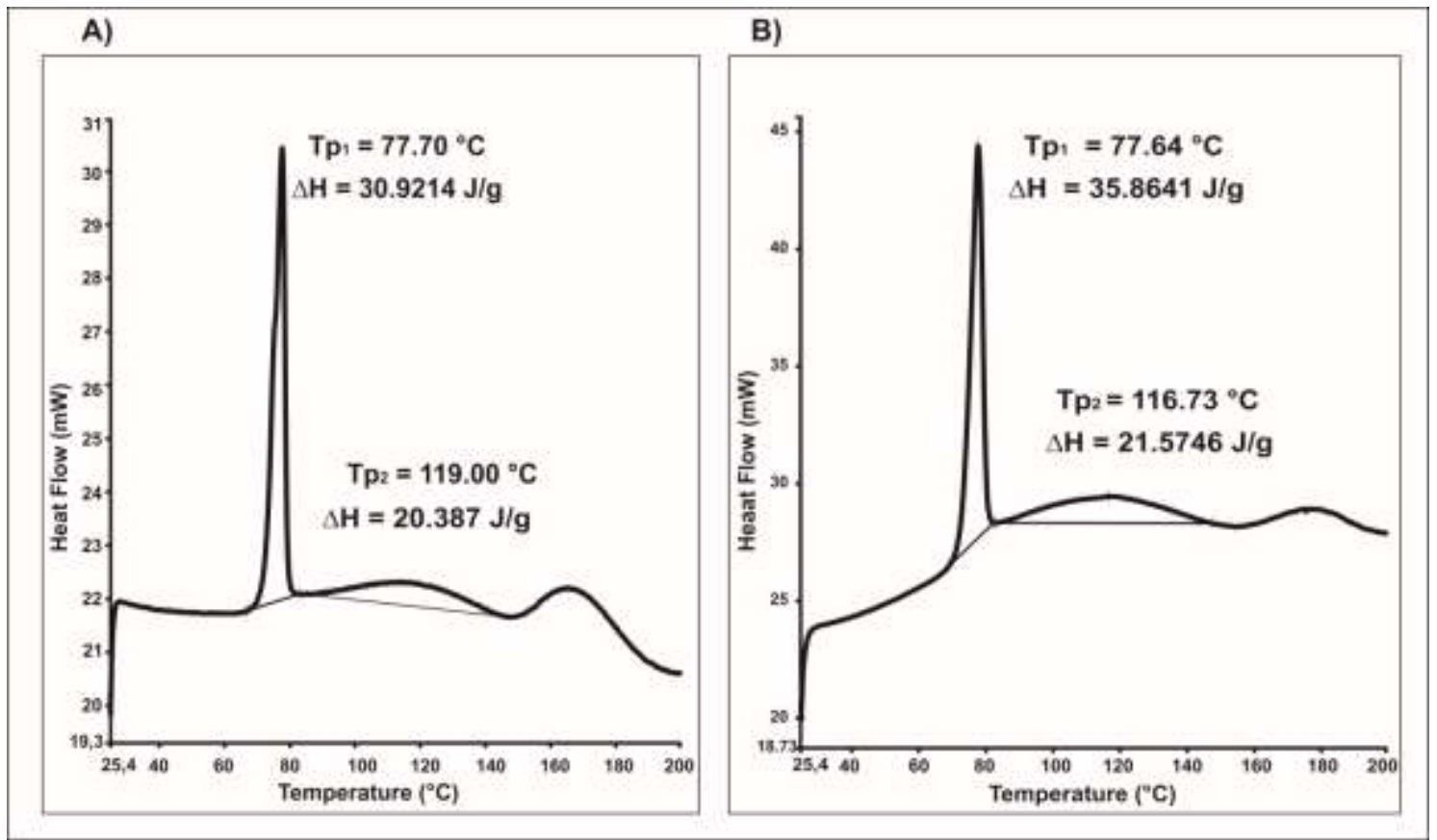

